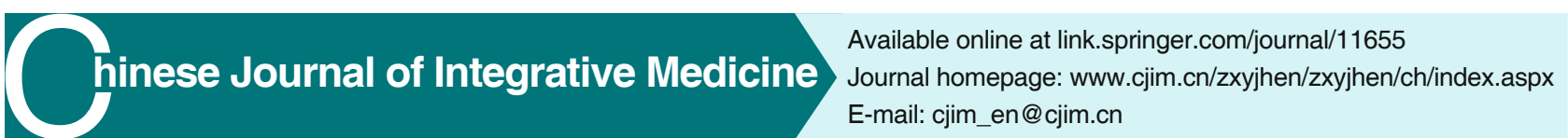

Original Article

\title{
In Silico Screening of Natural Products as Potential Inhibitors of SARS-CoV-2 Using Molecular Docking Simulation
}

\author{
Rajib Hossain ${ }^{1}$, Chandan Sarkar ${ }^{1}$, Shardar Mohammad Hafiz Hassan ${ }^{1}$, Rasel Ahmed Khan ${ }^{2}$, \\ Mohammad Arman ${ }^{3}$, Pranta Ray ${ }^{4}$, Muhammad Torequl Islam ${ }^{1}$, Sevgi Durna Daştan ${ }^{5,6}$, Javad Sharifi-Rad ${ }^{7}$, \\ Zainab M. Almarhoon ${ }^{8}$, Miquel Martorell ${ }^{9}$, William N. Setzer ${ }^{10,11}$, and Daniela Calina ${ }^{12}$
}

\begin{abstract}
Objective: To explore potential natural products against severe acute respiratory syndrome coronavirus (SARS-CoV-2) via the study of structural and non-structural proteins of human coronaviruses. Methods: In this study, we performed an in-silico survey of 25 potential natural compounds acting against SARS-CoV-2. Molecular docking studies were carried out using compounds against 3-chymotrypsin-like protease $\left(3 \mathrm{CL}^{\mathrm{PRO}}\right)$, papain-like protease $\left(\mathrm{PL}^{\mathrm{PRO}}\right)$, RNA-dependent RNA polymerase (RdRp), non-structural protein (nsp), human angiotensin converting enzyme 2 receptor (hACE2R), spike glycoprotein (S protein), abelson murine leukemia viral oncogene homolog 1 (ABL1), calcineurin-nuclear factor of activated T-cells (NFAT) and transmembrane protease serine 2. Results: Among the screened compounds, amentoflavone showed the best binding affinity with the $3 \mathrm{CL}^{\mathrm{PRO}}$, RdRp, nsp13, nsp15, hACE2R, ABL1 and calcineurin-NFAT; berbamine with hACE2R and ABL1; cepharanthine with nsp10, nsp14, nsp16, S protein and ABL1; glucogallin with nsp15; and papyriflavonol $A$ with $\mathrm{PL}^{\mathrm{PRO}}$ protein. Other good interacting compounds were juglanin, betulinic acid, betulonic acid, broussooflavan A, tomentin A, B and E, 7-methoxycryptopleurine, aloe emodin, quercetin, tanshinone I, tylophorine and furruginol, which also showed excellent binding affinity towards a number of target proteins. Most of these compounds showed better binding affinities towards the target proteins than the standard drugs used in this study. Conclusion: Natural products or their derivatives may be one of the potential targets to fight against SARS-CoV-2.

KEYWORDS SARS-CoV-2, natural products-derived anti-SARS-CoV-2 candidates, structural proteins, nonstructural proteins, molecular docking
\end{abstract}

New coronavirus SARS-CoV-2 are singlestranded RNA genome-containing viruses with medical and veterinary importance. ${ }^{(1)}$ These include transmissible gastroenteritis virus, porcine epidemic diarrhea virus, and the human CoVs. The SARS-CoV-2 belongs to the betacoronavirus genus similar to severe acute respiratory syndrome coronavirus, and the Middle East respiratory syndrome coronavirus. ${ }^{(1,2)}$ The human coronaviruses SARS-CoV-2 are positive-sense with a length of $30,000 \mathrm{bp}$ and single-stranded RNA viruses. ${ }^{(3)}$

The two groups of proteins characterized in SARS-CoV-2 are (i) structural proteins (e.g., spike $(\mathrm{S})$, nucleocapsid $(\mathrm{N})$, matrix $(\mathrm{M})$ and envelope $(\mathrm{E})$ ) and (ii) non-structural proteins (e.g., proteases, 3-chymotrypsin-like protease $\left(3 \mathrm{CL}^{\mathrm{PRO}}\right)$, papain-like protease $\left(\mathrm{PL}^{\mathrm{PRO}}\right)$ and RNA-dependent RNA polymerase (RdRp). ${ }^{(1)}$ The CoV polyprotein encodes two proteases like $3 \mathrm{CL}^{\mathrm{PRO}}$, and $\mathrm{PL}^{\mathrm{PRO}}$ which share in its processing and release of the translated non-structural proteins. ${ }^{(4)}$
(C)The Chinese Journal of Integrated Traditional and Western Medicine Press and Springer-Verlag GmbH Germany, part of Springer Nature 2021

1. Department of Pharmacy, Life Science Faculty, Bangabandhu Sheikh Mujibur Rahman Science and Technology University, Gopalganj (8100), Bangladesh; 2. Harmacy Discipline, Life Science School, Khulna University, Khulna-9280, Bangladesh; 3. Department of Pharmacy, International Islamic University, Chittagong, Bangladesh; 4. Department of Biomedical Engineering, Huazhong University of Science and Technology, Wuhan (430074), China; 5. Department of Biology, Faculty of Science, Sivas Cumhuriyet University, Sivas (58140), Turkey; 6. Beekeeping Development Application and Research Center, Sivas Cumhuriyet University, Sivas (58140), Turkey; 7. School of Medicine, University of Azuay, Cuenca, Ecuador; 8. Department of Chemistry, College of Science, King Saud University, Riyadh (11451), Saudi Arabia; 9. Department of Nutrition and Dietetics, Faculty of Pharmacy, and Centre for Healthy Living, University of Concepción, Concepción (4070386), Chile; 10. Department of Chemistry, University of Alabama in Huntsville, Huntsville, AL (35899), USA; 11. Aromatic Plant Research Center, $230 \mathrm{~N}$ 1200 E, Suite 100, Lehi, UT (84043), USA; 12. Department of Clinical Pharmacy, University of Medicine and Pharmacy of Craiova, Craiova (200349), Romania

Correspondence to: Prof. Javad Sharifi-Rad, E-mail: javad. sharifirad@gmail.com

DOI: https://doi.org/10.1007/s11655-021-3504-5 
The RdRp is a crucial viral enzyme in the life cycle of RNA viruses. ${ }^{(5)}$ The nsp12 is the polymerase that binds to its essential cofactors, nsp7 and nsp8. It is important in replication and transcription of the viral genome. $S$ protein is a crucial factor for viral attachment and entry to the host cells, which present on the outer surface of the virion, in a homo-trimeric state. ${ }^{(6)} 3 \mathrm{CL}^{\mathrm{PRO}}$ is the main protease that cleaves host polyproteins into viral replication-related proteins, and is highly conserved across the SARS-CoV-2 family, including SARS-CoVs and Middle East respiratory syndrome corona. ${ }^{(7)}$ The $\mathrm{PL}^{\mathrm{PRO}}$ cleaves the nsp1/2, nsp2/3 and nsp3/4 boundaries. It works with $3 \mathrm{CL}^{\mathrm{PRO}}$ to cleave the polyproteins into nsps. ${ }^{\left({ }^{8}\right)}$ The nsp13 (helicase) catalyzes the unwinding of duplex oligonucleotides into single strands in a nucleoside 5'-triphosphate (NTP)dependent manner. It is also an ideal target to develop antiviral drugs due to its sequence conservation in all CoV species. ${ }^{(9)}$ The $\mathrm{N}$-terminal exoribonuclease and C-terminal guanine-N7 methyl transferase (nsp14) of $\mathrm{CoV}$ is important for viral replication and transcription. ${ }^{(10)}$

The N-terminal exoribonuclease domain plays a proofreading role in prevention of the lethal mutagenesis, and the C-terminal domain functions as a guanine-N7 methyl transferase for mRNA capping. ${ }^{(11)}$ The nsp15 forms a hexameric endoribonuclease that preferentially cleaves $3^{\prime}$ of uridines, also named as uridylate-specific endoribonuclease. It is one of the RNA-processing enzymes encoded by the CoV, ${ }^{(12)}$ while nsp16 is an S-adenosylmethionine dependent nucleoside-2'-O-methyltransferase. The latter one is only activated by the binding of nsp10. ${ }^{(13)}$ On the other hand, nsp10 is an essential co-factor and forms a complex with nsp14 and nsp16.

Development of new drugs against the SARSCoV-2 focuses on blocking virus entry into the host cells, and preventing viral transcription and replication. The $3 C^{P R O}$, plays a pivotal role in mediating viral replication complex and transcription, is a particularly attractive target for anti-SARS-CoV-2 drug design. ${ }^{(14)}$ It has gained much attention as a valuable target in drug discovery efforts and also been termed 'the Achilles heel of coronaviruses'. ${ }^{(15)}$ In addition to 3-chymotrypsinlike protease $\left(3 \mathrm{CL}^{\mathrm{PRO}}\right)$, papain-like protease $\left(\mathrm{PL}^{\mathrm{PRO}}\right)$, and RNA-dependent RNA polymerase (RdRp), there are other target proteins, such as the receptor 2 of the human angiotensin-converting enzyme (hACE2R), calcineurin-activated nuclear $\mathrm{T}$ cell factor (NFAT) and murine abelson homologue 1 of the leukemia viral oncogene ( $A B L 1)$. Molecular docking simulations were used to perform in silico screening of potential active compounds against hACE2R, $3 \mathrm{CL}^{\mathrm{PRO}}, \mathrm{PL}^{\mathrm{PRO}}$, RdRp, nsp10, nsp13-16, calcineurin-NFAT, transmembrane protease serine 2 (TMPRSS2), and ABL1. ${ }^{(16-18)}$

In this respect, numerous plants containing high concentrations of flavonoids and polyphenolic compounds are known to have antioxidant, anticancer, anti-depressant, anti-inflammatory, anti-diarrheal, antidiabetic, and anti-viral effects. Furthermore, a recent study showed that above mentioned compounds exert anti-SARS-CoV-2 activity with inhibitory concentration 50/effective concentration 50 less than $10 \mu \mathrm{mol} / \mathrm{L} .{ }^{(19)}$ In this study, we have performed an in silico survey of 25 potential natural products acting against SARSCoV-2 and compared the data with antiviral drugs as standards (Appendix 1).

\section{METHODS}

\section{In Silico Prediction of Activity Spectra for Substances}

Prediction of antiviral activity of 25 potential natural products was carried out using the "prediction of activity spectra for the substances" (PASS) computer program. This software estimates predicted activity spectrum of a compound as probable activity $(\mathrm{Pa})$ and probable inactivity $(\mathrm{Pi})$. The values of $\mathrm{Pa}$ and $\mathrm{Pi}$ vary between 0.000 and 1.000. Only activities with $\mathrm{Pa}>\mathrm{Pi}$ are considered as possible for a particular compound. If $\mathrm{Pa}>0.7$, the probability of experimental pharmacological action is high and if $0.5<\mathrm{Pa}<0.7$, probability of experimental pharmacological action is less. If the value of $\mathrm{Pa}<0.5$, the chance of experimentally finding the activity is less, but it may also indicate a chance of finding a new lead compound. ${ }^{(20)}$

\section{Macromolecules and Preparation}

Glide of Schrödinger-Maestro (version 11.1, https://www.schrodinger.com/products/maestro, Schrodinger, USA)) was used for the molecular docking analysis to predict the behavior of the mentioned compounds against the macromolecular targets of the human coronavirus: $3 \mathrm{CL}^{\mathrm{PRO}}$ (PDB 6LU7), $\mathrm{PL}^{\mathrm{PRO}}$ (PDB 4OW0), hACE2R (PDB 2AJF), RdRp (PDB 6NUR), $S$ protein (PDB 2GHV), nsp13 (PDB 6JYT), nsp14 (PDB 5C8S), nsp15 (PDB 2H85), nsp16 (PDB 3R24), nsp10 (PDB 2XYR), calcineurin-NFAT (PDB 2JOG), ABL1 (PDB 6T3B) and TMPRSS2 (PDB 2OQ5, Appendix 2). 
For the purpose of energy minimization crystal structure, we utilized Swiss-PDB Viewer software package (version 4.1.0, Structural Bioinformatics Group, SIB Swiss Institute of Bioinformatics, Switzerland), and then all the hetero atoms and water molecules of proteins were removed by using PyMOI (version 1.7.4.5, BIOVIA, Schrodinger, USA) before docking. A simple docking method was used to explore the properties of our Gaussian Scoring Function, i.e., a Quasi-Newton solid body optimization of the ligand location from random starting positions near the receptor site. ${ }^{(21)}$ The receptor grid generation was done by PockDrug selecting the best binding sites.

\section{Ligand Preparation}

Twenty-five natural compounds (Appendix 3) and commercially available antiviral drugs (i.e., alisporivir, chloroquine, cyclosporine, favipiravir, grl0617, lopinavir, remdesivir, ritonavir, selumetinib, trametinib, Table 2) were downloaded from the PubChem (a database for chemical molecules). By using Gaussian view 09 package (Gaussian Inc, USA) and Chem3D Pro12.0 program (University of Bath, England) package, all internal energies of the ligands were optimized.

\section{Active Site and Grid Generation}

The Van der Waals scaling factor 1.00 and charge cutoff 0.25 subjected to OPLS 2005 force field. The bounding box was set to $15 \times 15 \times 15$ for the docking study.

\section{Docking Analysis and Binding Site}

The actives sites are the coordinates of the ligand in the original target protein grids and these active binding sites of target protein were scrutinized using Drug Discovery Studio version 4.5 (BIOVIA Dassault Systèmes, USA). The non-covalent interactions were calculated using Discovery Studios Software (Biovia, England).

\section{RESULTS}

\section{Docking with Non-structural Proteins Interaction with $3 \mathrm{CL}^{\mathrm{PRO}}$}

Amentoflavone, berbamine, cepharanthine, glucogallin, juglanin and papyriflavonol $A$ exhibited binding affinities with $3 \mathrm{CL}^{\mathrm{PRO}}$ (Table 1). Amentoflavone showed the highest binding energy compared to the other compounds. The 2D and 3D structures of nonbond interactions of amentoflavone with $3 \mathrm{CL}^{\mathrm{PRO}}$ are shown in Appendix 4. The standard drugs ritonavir and lopinavir showed binding affinities towards $3 \mathrm{CL}^{\mathrm{PRO}}$ by -6.8 and $-6.5 \mathrm{kcal} / \mathrm{mol}$, respectively (Table 2 ). The 2D and 3D structures of non-bond interactions of ritonavir with $3 \mathrm{CL}^{\mathrm{PRO}}$ are shown in Appendix 5 .

Interaction with $\mathrm{PL}^{\mathrm{PRO}}$

Amentoflavone, broussoflavan A, cepharanthine,

Table 1. Natural Products-Derived Compounds Showing Highest Binding Affinity with SARS-CoV-2 Non-structural Proteins

\begin{tabular}{|c|c|c|c|c|c|c|c|c|}
\hline \multirow[b]{2}{*}{ Compounds } & \multicolumn{8}{|c|}{ Binding affinity $(\mathrm{kcal} / \mathrm{mol})$} \\
\hline & $\begin{array}{l}3 \mathrm{CL}^{\mathrm{PRO}} \\
(6 \mathrm{LU} 7)\end{array}$ & $\begin{array}{c}\mathrm{PL}^{\mathrm{PRO}} \\
(4 \mathrm{OWO})\end{array}$ & $\begin{array}{l}\text { RdRp } \\
\text { (6NUR) }\end{array}$ & $\begin{array}{l}\text { nsp10 } \\
\text { (2XYR) }\end{array}$ & $\begin{array}{l}\text { Helicase } \\
\text { (6JYT) }\end{array}$ & $\begin{array}{l}\text { nsp14 } \\
\text { (5C8S) }\end{array}$ & $\begin{array}{l}\text { nsp15 } \\
\text { (2H85) }\end{array}$ & $\begin{array}{l}\text { nsp16 } \\
\text { (3R24) }\end{array}$ \\
\hline 7-Methoxycryptopleurine & - & - & -8.4 & - & - & - & -8.6 & - \\
\hline Aloe emodin & - & - & -8.0 & - & - & - & -8.8 & -8.0 \\
\hline Amentoflavone & -9.7 & -8.2 & -10.5 & -8.2 & -9.8 & -8.5 & -10.5 & -9.3 \\
\hline Berbamine & -8.6 & - & -8.6 & -7.9 & -8.9 & - & -9.1 & - \\
\hline Betulinic acid & - & - & -9.6 & - & -9.4 & - & - & - \\
\hline Betulonic acid & - & - & - & -7.8 & -9.3 & -7.7 & & - \\
\hline Broussoflavan A & - & -8.5 & - & - & - & - & -9.1 & - \\
\hline Cepharanthine & -8.6 & -8.1 & -9.6 & -8.3 & -9.3 & -9.2 & -9.3 & -10.4 \\
\hline Glucogallin & -8.2 & - & -9.6 & - & -9.4 & - & -10.4 & - \\
\hline Juglanin & -8.1 & -7.8 & - & - & - & - & - & \\
\hline Papyriflavonol A & -8.3 & -8.6 & & -7.9 & -8.2 & & - & -8.5 \\
\hline Quercetin & - & - & - & - & - & - & - & -9.0 \\
\hline Tanshinone I & - & - & - & - & -8.0 & - & -8.5 & -8.8 \\
\hline Tomentin A & - & - & - & - & -8.0 & - & -9.3 & -9.2 \\
\hline Tomentin B & - & - & - & - & -8.3 & -7.7 & - & -8.8 \\
\hline Tomentin E & - & - & -8.5 & - & -8.0 & - & -9.1 & -8.6 \\
\hline
\end{tabular}


Table 2. Binding Affinities of Some Standard Drugs with Respective Targets of SARS-CoV-2

\begin{tabular}{|c|c|c|c|c|c|c|}
\hline \multirow[b]{2}{*}{ Standards } & \multicolumn{5}{|c|}{ Binding affinity $(\mathrm{kcal} / \mathrm{mol})$} & \multirow[b]{2}{*}{ Interacting amino acid residues } \\
\hline & $\begin{array}{l}3 \mathrm{CL}^{\mathrm{PRO}} \\
(6 \mathrm{LU} 7) \\
\end{array}$ & $\begin{array}{l}\mathrm{PL}^{\mathrm{PRO}} \\
\text { (4OW0) }\end{array}$ & $\begin{array}{l}\text { RdRp } \\
\text { (6NUR) }\end{array}$ & $\begin{array}{c}\text { NFAT } \\
\text { (2JOG) }\end{array}$ & $\begin{array}{c}\mathrm{ABL1} \\
(6 \mathrm{~T} 3 \mathrm{~B}) \\
\end{array}$ & \\
\hline Ritonavir & -6.8 & & & & & Phe294, Gly109, Asn203, Thr292, Pro293, Val104, Arg105, Val297 \\
\hline Lopinavir & -6.5 & -6.8 & & & & Iva159 Glu168 SIn270 Acn165 Tyr265 Tyr260 \\
\hline GRL0617 & & -6.5 & & & & Lys158, Glu168, Ginz/0, Asp165, Iyr265, Iyr269 \\
\hline Chloroquine & & & -6.1 & & & \\
\hline Remdesivir & & & -7.8 & & & Gln724, Leu708, Ala125, Val128, Tyr129, His133, His725, Tyr728 \\
\hline Favipiravir & & & -5.5 & & & \\
\hline Alisporivir & & & & -6.8 & & \\
\hline Cyclosporine & & & & -6.7 & & Tyr159, Leu156, Pro344, His151, Phe160, Trp232 \\
\hline Trametinib & & & & & -9.2 & Ivs298. Asn299 Glu852 Glu880 His295 Ara849 \\
\hline Selumetinib & & & & & -5.9 & LyS298, ASn299, GIU852, Giu880, HIS295, Arg84Y \\
\hline
\end{tabular}

papyriflavonol $A$ and juglanin showed good binding affinity with $\mathrm{PL}^{\mathrm{PRO}}$ (Table 1). The 2D and 3D structures of non-bond interactions of these compounds with $\mathrm{PL}^{\mathrm{PRO}}$ are shown in Appendix 4. The standard drugs, lopinavir and GRL0617 showed binding affinities towards $\mathrm{PL}^{\mathrm{PRO}}$ by -6.8 and $-6.5 \mathrm{kcal} / \mathrm{mol}$, respectively (Table 2 ). The 2D and 3D structures of non-bond interactions of lopinavir with $\mathrm{PL}^{\mathrm{PRO}}$ are shown in Appendix 5.

\section{Interaction with RdRp}

7-Methoxycryptopleurine, aloe emodin, amentoflavone, berbamine, betulinic acid, broussoflavan $A$, cepharanthine, ferruginol, juglanin, papyriflavonol $A$, tanshinone $I$, tomentin $A, B$ and $E$ displayed binding affinities with RdRP (Table 1). Among those compounds, amentoflavone exhibited strong binding energy with RdRp protein (Appendix 4). The standard drugs, chloroquine, remdesivir and favipiravir showed binding affinities towards RdRp by $-6.1,-7.8$ and $-5.5 \mathrm{kcal} / \mathrm{mol}$, respectively (Table 2 ). The $2 \mathrm{D}$ and $3 \mathrm{D}$ structures of non-bond interactions of remdesivir with RdRp are shown in Appendix 5.

\section{Interaction with nsp10}

The binding affinities of amentoflavone, berbamine, betulonic acid, cepharanthine and papyriflavonol $A$ with nsp10 are shown in Table 1. Cepharanthine exhibited best the binding interaction with nsp10 (Appendix 4).

\section{Interaction with nsp13}

Molecular docking against nsp13 (helicase, PDB 6JYT) indicated that amentoflavone, berbamine, betulinic acid, betulonic acid, broussoflavan A, cepharanthine, glucogallin, papyriflavonol A, tanshinone I, tomentin $\mathrm{A}, \mathrm{B}$ and $\mathrm{E}$ exhibited the binding affinities with nsp 13 (Table 1). In comparison to the other compounds, amentoflavone displayed the best binding affinity with this helicase protein (Appendix 4).

\section{Interaction with nsp14}

Amentoflavone, betulonic acid, cepharanthine and tomentin $B$ exhibited binding affinities with nsp14 (Table 1). Cepharanthine showed a good binding interaction with nsp14 with a single hydrogen bond with Pro84, van der Waals bond with Asn85, and alkyl bonds with Leu92 and Leu112 amino acid residues (Appendix 4). On the other hand, amentoflavone bound with Asp91 and Cys90 through 2 hydrogen bonds, while betulonic acid with Thr5, Gly70, Ala71 and Lys95 and tomentin B with Asn85, Asp91, Phe89 and Cys74 though 4 hydrogen bonds.

\section{Interaction with nsp15}

7-Methoxycryptopleurine, aloe emodin, amentoflavone, berbamine, broussoflavan $A$, cepharanthine, glucogallin, tanshinone I, tomentin A and $E$ exhibited binding affinities with $n s p 15$, respectively (Table 1). Amentoflavone and glucogallin showed the best binding energies, -10.5 and $-10.4 \mathrm{kcal} / \mathrm{mol}$, respectively. The 2D and 3D structures of non-bond interactions of amentoflavone and glucogallin with nsp15 are shown in Appendix 4.

\section{Interaction with nsp16}

The binding affinities of aloe emodin, amentoflavone, cepharanthine, papyriflavonol A, quercetin, tanshinone $I$, tomentin $A, B$ and $E$ were shown in Table 1. Cepharanthine exhibited a stronger binding capacity with nsp16 (PDB 3R24) than the other compounds. The 2D and 3D structures of non- 
Table 3. Compounds Showing the Highest Binding Affinity with SARS-CoV-2 Structural Proteins and Other Host Proteins

\begin{tabular}{|c|c|c|c|c|c|}
\hline \multirow{2}{*}{ Compounds } & \multicolumn{5}{|c|}{ Binding affinity $(\mathrm{kcal} / \mathrm{mol})$} \\
\hline & hACE2R (2AJF) & S protein (2GHV) & ABL1 (6T3B) & Calcineurin-NFAT (2JOG) & TMPRSS2 (2OQ5) \\
\hline 7-Methoxycryptopleurine & - & - & -8.6 & - & - \\
\hline Aloe emodin & - & - & -8.7 & - & - \\
\hline Amentoflavone & -10.1 & -9.5 & -11.5 & -10.3 & -9.2 \\
\hline Berbamine & -10.0 & -8.3 & -10.2 & - & - \\
\hline Betulinic acid & -8.1 & - & -9.5 & -8.8 & - \\
\hline Betulonic acid & -8.1 & - & -8.8 & -9.0 & - \\
\hline Cepharanthine & -9.0 & -9.7 & -11.8 & -9.0 & -8.3 \\
\hline Ferruginol & - & -8.0 & - & - & - \\
\hline Glucogallin & -9.1 & - & -10.0 & -9.2 & -8.7 \\
\hline Juglanin & - & - & -8.6 & - & -8.2 \\
\hline Papyriflavonol A & -8.5 & -8.4 & -9.6 & -8.6 & - \\
\hline Quercetin & - & - & -8.6 & - & -8.0 \\
\hline Tanshinone I & - & -8.5 & -9.2 & - & - \\
\hline Tomentin A & -8.4 & - & -9.6 & - & -8.5 \\
\hline Tomentin B & - & -8.1 & - & - & -8.9 \\
\hline Tomentin E & -8.5 & - & - & -8.6 & - \\
\hline Tylophorine & - & - & -8.5 & - & - \\
\hline
\end{tabular}

bonding interactions of cepharanthine the nsp16 are given in Appendix 4.

\section{Docking with Structural Proteins Interaction with hACE2R}

Amentoflavone, berbamine, betulinic acid, betulonic acid, cepharanthine, glucogallin, papyriflavonol $A$, tomentin $A$ and $E$ exhibited binding affinity with hACE2R protein (Table 3 ). Amentoflavone and berbamine displayed the best binding affinity with hACE2R (Appendix 6).

\section{Interaction with S protein}

The binding affinities of amentoflavone, berbamine, cepharanthine, ferruginol, papyriflavonol $A$, tanshinone I and tomentin B are shown in Table 3. Cepharanthine exhibited the best binding affinity with the SARS-CoV-2 S protein (PDB 2GHV) than the other compounds. The interactions of cepharanthine with the spike glycoprotein include 2 pi-pi bonds with Phe364 and Phe361 as well as 1 alkyl bond with Leu355 amino acid residues (Appendix 6).

\section{Interaction with $\mathrm{ABL} 1$}

The binding affinities of 7-methoxycryptopleurine, aloe emodin, amentoflavone, berbamine, betulinic acid, betulonic acid, cepharanthine, juglanin, papyriflavonol $A$, quercetin, tanshinone I, tomentin A, tylophorine are shown in Table 3. In comparison with cepharanthine, other compounds showed lower binding affinity with ABL1 protein (Appendix 6). The standard drugs, trametinib and selumetinib showed binding affinities towards $A B L 1$ by -9.2 and $-5.9 \mathrm{kcal} / \mathrm{mol}$, respectively (Table 2). The 2D and 3D structures of non-bond interactions of trametinib with $A B L 1$ are shown in Appendix 5.

\section{Interaction with Calcineurin-NFAT}

Amentoflavone, betulinic acid, betulonic acid, cepharanthine, papyriflavonol A, tomentin A and $E$ exhibited binding affinity with the calcineurin-NFAT protein (Table 3). Amentoflavone showed the best binding energy as compared to the other compounds against this protein. The 2D and 3D structures of non-bonding interactions between amentoflavone and calcineurinNFAT protein are shown in Appendix 6. The standard drugs alisporivir and cyclosporine showed binding affinities towards NFAT by -6.8 and $-6.7 \mathrm{kcal} / \mathrm{mol}$, respectively (Table 2). The $2 \mathrm{D}$ and $3 \mathrm{D}$ structures of non-bond interactions of alisporivir with NFAT are shown in Appendix 5.

\section{Interaction with TMPRSS2}

Amentoflavone, cepharanthine, glucogallin, 
juglanin, quercetin, tomentin $A$ and $B$ displayed binding affinity with TMPRSS2 (PDB 2OQ5, Table 3). The amentoflavone showed the best binding energy as compared to the other compounds against this protein. Tomentin $B$ and glucogallin showed interaction with Glu218, Trp215 and Val227, and His99, Glu216, Cys219, Gln192, Ser195, Thr62, Cys58, Gly216, Cys191, His57 and Thr61, respectively (Appendix 6).

\section{DISCUSSION}

For controlling the outbreak of SARS-CoV-2, the researchers are working diligently to discover antiSARS-CoV-2 agents. For this purpose, medicinal plantderived compounds (phytochemical) may be a potential source of the lead compounds to combat the SARSCoV-2 infection. ${ }^{(23)}$ There are 12 targets for creating antiviral agents against SARS-CoV-2. The SARSCoV-2 polyprotein have 2 proteases. ${ }^{(4)} 3 \mathrm{CL}^{\mathrm{PRO}}$ is highly conserved across the SARS-CoV-2 family, ${ }^{(7)}$ and plays a pivotal role in mediating viral replication complex and transcription, is a particularly attractive target for the anti-CoV drug design. ${ }^{(14)}$ In our study, amentoflavone, berbamine, cepharanthine, glucogallin, juglanin and papyriflavonol A exhibited the good binding affinities with $3 \mathrm{CL}^{\mathrm{PRO}}$, amentoflavone, broussoflavan $\mathrm{A}$, cepharanthine, papyriflavonol $A$ and juglanin showed good binding affinity with $\mathrm{PL}^{\mathrm{PRO}}$. Amentoflavone showed strong binding capacity with both of $3 \mathrm{CL}^{\mathrm{PRO}}$ and $\mathrm{PL}^{\mathrm{PRO}}$ proteins.

SARS-CoV-2 utilize RdRp as a crucial enzyme in their life cycle. ${ }^{(5)}$ Therefore, RdRp can be one of the best targets for the discovery of antiviral drug against SARS-CoV-2. In this study, 7-methoxycryptopleurine, aloe emodin, amentoflavone, berbamine, betulinic acid, broussoflavan A, cepharanthine, ferruginol, juglanin, papyriflavonol $A$, tanshinone $I$, tomentin $A, B$ and $E$ showed good binding affinity with tRdRp protein, where amentoflavone exhibited a strong binding energy with this protein. Moreover, the nsp10, nsp13, nsp14, nsp15, and nsp16 also play an important role in SARS-CoV-2 infection. In this study, we found a number of compounds interact with these proteins, such as cepharanthine with nsp10 and nsp14, amentoflavone with nsp13 and nsp15, and papyriflavonol A with nsp16 proteins.

The SARS-CoV-2 could possibly use hACE2R for attaching in human lung cells. ${ }^{(24)}$ Therefore, hACE2R might be another potential target for inhibiting the viral attachment with the host cells. ${ }^{(16-18)}$ Our results demonstrate that amentoflavone, berbamine, betulinic acid, betulonic acid, cepharanthine, glucogallin, papyriflavonol $A$, tomentin $A$ and $E$ exhibited good binding affinity with hACE2R protein, where amentoflavone and berbamine showed a strong binding capacity with this protein. Moreover, ABL1 and calcineurin-NFAT also play an important role in SARS-CoV-2 infection. In this study, we found a number of compounds interact with these proteins, such as cepharanthine with $A B L 1$, and betulonic acid and cepharanthine with calcineurin - NFAT protein.

The biflavonoid derivative, amentoflavone is evident to inhibit SARS-CoV-2 $3 \mathrm{CL}^{\text {PRO }}$ with $8.3 \mu \mathrm{mol} / \mathrm{L} .{ }^{(25)}$ Amentoflavone has good interaction with $3 \mathrm{CL}^{\mathrm{PRO}}$, thereby suggesting an agreement with the previous study on this anti-CoV-2 agent. Additionally, it was also found to interact with the $\mathrm{PL}^{\mathrm{PRO}}$, hACE2R, RdRp, $S$ protein, nsps, ABL1 and NFAT protein. The antiviral effect of berbamine is undefined in the HCoV-NL63 model at $1.48 \mu \mathrm{mol} / \mathrm{L} .{ }^{(22)}$ In our study, berbamine showed good binding affinity with $3 \mathrm{CL}^{\mathrm{PRO}}$, hACE2R, RdRp, S protein, nsp10, nsp13, and nsp15 and $A B L 1$ protein. On the other hand, cepharanthine and papyriflavonol A were shown to inhibit $3 \mathrm{CL}^{\mathrm{PRO}}$ and $\mathrm{PL}^{\mathrm{PRO}}$, respectively. ${ }^{(26,27)}$ Our in silico study also demonstrates that these two compounds exhibited significant binding affinity with $3 \mathrm{CL}^{\mathrm{PRO}}$ and $\mathrm{PL}^{\mathrm{PRO}}$. Additionally, they also showed binding affinity towards hACE2R, RdRp, S protein, nsps, ABL1 and NFAT protein.

Juglanin evidently blocks the $3 a$ channel in a SARS-CoV-2 model. ${ }^{(28)}$ Our study reports it also has binding affinities towards the $3 \mathrm{CL}^{\mathrm{PRO}}, \mathrm{PL}^{\mathrm{PRO}}$, RdRp and $A B L 1$ proteins. On the other hand, glucogallin blocked viral entry in SARS-CoV-2 model. ${ }^{(29)}$ In this study, this complex compound displayed binding affinity with the $3 L^{\text {PRO }}, \mathrm{hACE} 2 \mathrm{R}, \mathrm{nsp} 13$, and nsp15. Broussoflavan $A$ can inhibit $\mathrm{PL}^{\mathrm{PRO}}$ (27) $^{(27}$ Beside this, we found that it has binding affinities towards RdRp, hACE2R, nsp13 and nsp15 proteins. Betulinic acid inhibit viral replication at $0.63 \mu \mathrm{mol} / \mathrm{L}$, while betulonic acid inhibited $3 \mathrm{CL}^{\mathrm{PRO}}$ at $10 \mu \mathrm{mol} / \mathrm{L}$ in a SARS-CoV-2 model. ${ }^{(30)}$ Our study demonstrates these compounds have binding affinity towards hACE2R, RdRp, nsp13, ABL1 and NFAT proteins. Tanshinone I inhibited SARS-CoV-2 viral infection and replication. ${ }^{(31)}$ In this study, it has been found to interact with hACE2R, RdRp, S protein, nsp13, nsp15 and nsp16, and ABL1 proteins. Tomentin A, B and $E$ can inhibit of $\mathrm{PL}^{\mathrm{PRO}}{ }^{(32)}$ In this in silico study, these tomentins also found to show good binding affinity towards the $\mathrm{PL}^{\mathrm{PRO}}$ as well as hACE2R, RdRp, nsp13, 
nsp15 and nsp16, ABL1, NFAT and S glycoprotein. In a SARS-CoV-2 model, aloe emodin exhibited inhibitory effect against $3 C L^{\text {PRO }}{ }^{\left({ }^{(3)}\right)}$ Here we found its good interaction capacity with the RdRp, nsp15 and ABL1 protein.

Furruginol can inhibit SARS-CoV-2 replication. ${ }^{(30)}$ Our study reports it has good binding affinity towards RdRp and S glycoprotein. 7-Methoxycryptopleurine and tylophorine are evident to inhibit SARS-CoV-2 protease, respectively. ${ }^{(34)}$ We found that these two compounds showed binding affinity against RdRp, nsp15 and ABL1 proteins. The TMPRSS-2 facilitates SARS-CoV-2, including SARS-CoV-2 infections via 2 independent mechanisms: (i) proteolytic cleavage of hACE2R which promotes viral uptake, and (ii) cleavage of SARS-CoV-2 $S$ proteins which activates glycoprotein for host cell entry. ${ }^{(35)}$ It has been also suggested that the intestine is one of the potential sites of SARS-CoV-2 replication, that may contribute to local and systemic illness and overall disease progression in SARS-CoV-2. In a recent study, besides TMPRSS2, TMPRSS4 was seen to facilitate SARS-CoV-2 spike fusogenic activity, thereby promoting viral entrance into the host cell. ${ }^{(36)}$

In this study, amentoflavone, cepharanthine, glucogallin and tomentin A, showing best binding affinities towards hACE2R, have also been evident to show good bindings capacity towards TMPRSS2. Moreover, the compounds such as amentoflavone, cepharanthine, ferruginol, and tomentin B showing the best binding affinities towards $S$ protein also showed good bindings capacity towards TMPRSS2. Quercetin also showed good binding affinity towards this protein.

The main strengths of this research derive from our findings which suggest that the studied natural derivatives compounds can be considered as potential adjuvant treatment against SARS-CoV-2. Therefore, (i) amentoflavone may act through inhibiting the $3 \mathrm{CL}^{\mathrm{PRO}}$, RdRp, nsp13, nsp15, hACE2R, ABL1 and calcineurinNFAT protein; (ii) berbamine may inhibit hACE2R and ABL1 protein; (iii) cepharanthine may interact with nsp10, nsp14, nsp16, Spike and ABL1 protein; (iv) papyriflavonol A may interact with $\mathrm{PL}^{\mathrm{PRO}}$ protein; (v) glucogallin may interact with nsp15 protein of SARSCoV-2. Also, our findings will be helpful for further preclinical and clinical studies with these compounds and will be able to inspire medicinal scientists to conduct adequate research on the natural products and their derivatives as novel anti-viral agents against the SARS-CoV-2.

\section{Conflict of Interest}

The authors declare no conflict of interest.

\section{Author Contributions}

Conceptualization: MTI; formal analysis: CS; investigation: $\mathrm{RH}, \mathrm{CS}, \mathrm{SMHH}, \mathrm{MA}$ and SDD; project administration: MTI and $\mathrm{J}$ S-R; writing-original draft: RH, RAK, PR, MTI, J S-R, and MM; Writing-review and editing: JS-R, DC, and WNS.

Electronic Supplementary Material: Supplementary materials (Appendices 1-6) are available in the online version of this article at DOI: https://doi.org/10.1007/s11655-021-3504-5

\section{REFERENCES}

1. Elfiky AA, Mahdy SM, Elshemey WM. Quantitative structure-activity relationship and molecular docking revealed a potency of anti-hepatitis C virus drugs against human corona viruses. J Med Virol 2017;89:1040-1047.

2. Robson B. Computers and viral diseases. Preliminary bioinformatics studies on the design of a synthetic vaccine and a preventative peptidomimetic antagonist against the SARS-CoV-2 (2019-nCoV, COVID-19) coronavirus. Comput Biol Med 2020;119:103670.

3. Calina D, Docea AO, Petrakis D, Egorov AM, Ishmukhametov AA, Gabibov AG, et al. Towards effective COVID-19 vaccines: updates, perspectives and challenges. Int J Mol Med 2020;46:3-16.

4. Hilgenfeld R. From SARS to MERS: crystallographic studies on coronaviral proteases enable antiviral drug design. FEBS J 2014;281:4085-4096.

5. Elfiky AA. Ribavirin, remdesivir, sofosbuvir, galidesivir, and tenofovir against SARS-CoV-2 RNA dependent RNA polymerase (RdRp): a molecular docking study. Life Sci 2020;253:117592.

6. Ratia K, Saikatendu KS, Santarsiero BD, Barretto N, Baker SC, Stevens RC, et al. Severe acute respiratory syndrome coronavirus papain-like protease: structure of a viral deubiquitinating enzyme. Proc Natl Acad Sci USA 2006;103:5717-5722.

7. Wu C, Liu Y, Yang Y, Zhang P, Zhong W, Wang Y, et al. Analysis of therapeutic targets for SARS-CoV-2 and discovery of potential drugs by computational methods. Acta Pharm Sin B 2020;10:766-788.

8. Báez-Santos YM, St John SE, Mesecar AD. The SARScoronavirus papain-like protease: structure, function and inhibition by designed antiviral compounds. Antivir Res 2015;115:21-38.

9. Ivanov KA, Ziebuhr J. Human coronavirus 229E nonstructural protein 13: characterization of duplex-unwinding, nucleoside triphosphatase, and RNA 5'-triphosphatase activities. J Virol 


\section{4;78:7833-7838.}

10. Jin $X$, Chen $Y$, Sun $Y$, Zeng $C$, Wang $Y$, Tao J, et al. Characterization of the guanine-N7 methyltransferase activity of coronavirus nsp14 on nucleotide GTP. Virus Res 2013;176:45-52.

11. Bouvet M, Imbert I, Subissi L, Gluais L, Canard B, Decroly E. RNA $3^{\prime}$-end mismatch excision by the severe acute respiratory syndrome coronavirus nonstructural protein nsp10/nsp14 exoribonuclease complex. Proc Natl Acad Sci USA 2012;109:9372-9377.

12. Ricagno S, Egloff M-P, Ulferts R, Coutard B, Nurizzo D, Campanacci V, et al. Crystal structure and mechanistic determinants of SARS coronavirus nonstructural protein 15 define an endoribonuclease family. Proc Natl Acad Sci USA 2006;103:11892.

13. Decroly E, Imbert I, Coutard B, Bouvet M, Selisko B, Alvarez $\mathrm{K}$, et al. Coronavirus nonstructural protein 16 is a cap-0 binding enzyme possessing (nucleoside-2'O)methyltransferase activity. J Virol 2008;82:8071-8084.

14. van der Hoek L, Pyrc K, Jebbink MF, Vermeulen-Oost W, Berkhout RJ, Wolthers KC, et al. Identification of a new human coronavirus. Nat Med 2004;10:368-373.

15. Berry M, Fielding BC, Gamieldien J. Potential broad spectrum inhibitors of the coronavirus $3 \mathrm{CL}^{\mathrm{PRO}}$ : a virtual screening and structure-based drug design study. Viruses 2015;7:6642-6660.

16. Ortega JT, Serrano ML, Pujol FH, Rangel HR. Role of changes in SARS-CoV-2 spike protein in the interaction with the human ACE2 receptor: an in silico analysis. EXCLI J 2020;19:410-417.

17. Zhao X, Chen D, Szabla R, Zheng M, Li G, Du P, et al. Broad and differential animal angiotensin-converting enzyme 2 receptor usage by SARS-CoV-2. J Virol 2020;94:e00940-e00920.

18. Bouricha EM, Hakmi M, Akachar J, Belyamani L, Ibrahimi A. In silico analysis of ACE2 orthologues to predict animal host range with high susceptibility to SARS-CoV-2. Biotech 2020;10:483.

19. Islam MT, Sarkar C, El-Kersh DM, Jamaddar S, Uddin SJ, Shilpi JA, et al. Natural products and their derivatives against coronavirus: a review of the non-clinical and preclinical data. Phytother Res 2020;34:2471-2492.

20. Singh D, Gawande DY, Singh T, Poroikov V, Goel RK. Revealing pharmacodynamics of medicinal plants using in silico approach: a case study with wet lab validation. Comput Biol Med 2014;47:1-6.

21. Aziz MA, Mehedi M, Akter MI, Sajon SR, Mazumder K, Rana MS. In vivo and in silico evaluation of analgesic activity of Lippia alba. Clin Phytosci 2019;5:38.

22. Shen L, Niu J, Wang C, Huang B, Wang W, Zhu N, et al. High-throughput screening and identification of potent broad-spectrum inhibitors of coronaviruses. J Virol 2019;93:e00023-e00019.

23. Jassim SA, Naji MA. Novel antiviral agents: a medicinal plant perspective. J Appl Microbiol 2003;95:412-427.
24. Wu K, Chen L, Peng G, Zhou W, Pennell CA, Mansky $L M$, et al. A virus-binding hot spot on human angiotensinconverting enzyme 2 is critical for binding of two different coronaviruses. J Virol 2011;85:5331-5337.

25. Ryu YB, Jeong HJ, Kim JH, Kim YM, Park JY, Kim D, et al. Biflavonoids from Torreya nucifera displaying SARS-CoV 3CL (pro) inhibition. Bioorg Med Chem 2010;18:7940-7947.

26. Zhang $\mathrm{CH}$, Wang YF, Liu XJ, Lu JH, Qian CW, Wan ZY, et al. Antiviral activity of cepharanthine against severe acute respiratory syndrome coronavirus in vitro. Chin Med $\mathrm{J}$ 2005;118:493-496.

27. Park JY, Yuk HJ, Ryu HW, Lim SH, Kim KS, Park KH, et al. Evaluation of polyphenols from Broussonetia papyrifera as coronavirus protease inhibitors. J Enzyme Inhib Med Chem 2017;32:504-515.

28. Schwarz S, Sauter D, Wang K, Zhang R, Sun B, Karioti A, et al. Kaempferol derivatives as antiviral drugs against the $3 \mathrm{a}$ channel protein of coronavirus. Planta Med 2014;80:177-182.

29. Yi L, Li Z, Yuan K, Qu X, Chen J, Wang G, et al. Small molecules blocking the entry of severe acute respiratory syndrome coronavirus into host cells. J Virol 2004;78:11334-11339.

30. Wen CC, Kuo YH, Jan JT, Liang PH, Wang SY, Liu HG, et al. Specific plant terpenoids and lignoids possess potent antiviral activities against severe acute respiratory syndrome coronavirus. J Med Chem 2007;50:4087-4095.

31. Park JY, Kim JH, Kim YM, Jeong HJ, Kim DW, Park KH, et al. Tanshinones as selective and slow-binding inhibitors for SARS-CoV cysteine proteases. Bioorg Med Chem 2012;20:5928-5935.

32. Cho JK, Curtis-Long MJ, Lee KH, Kim DW, Ryu HW, Yuk $\mathrm{HJ}$, et al. Geranylated flavonoids displaying SARS-CoV papain-like protease inhibition from the fruits of Paulownia tomentosa. Bioorg Med Chem 2013;21:3051-3057.

33. Lin CW, Tsai FJ, Tsai CH, Lai CC, Wan L, Ho TY, et al. Anti-SARS coronavirus $3 \mathrm{C}$-like protease effects of Isatis indigotica root and plant-derived phenolic compounds. Antivir Res 2005;68:36-42.

34. Yang CW, Lee YZ, Kang IJ, Barnard DL, Jan JT, Lin $D$, et al. Identification of phenanthroindolizines and phenanthroquinolizidines as novel potent anti-coronaviral agents for porcine enteropathogenic coronavirus transmissible gastroenteritis virus and human severe acute respiratory syndrome coronavirus. Antivir Res 2010;88:160-168.

35. Shulla A, Heald-Sargent T, Subramanya G, Zhao J, Perlman $\mathrm{S}$, Gallagher T. A transmembrane serine protease is linked to the severe acute respiratory syndrome coronavirus receptor and activates virus entry. J Virol 2011;85:873-882.

36. Zang R, Gomez Castro MF, McCune BT, Zeng Q, Rothlauf PW, Sonnek NM, et al. TMPRSS2 and TMPRSS4 promote SARS-CoV-2 infection of human small intestinal enterocytes. Sci Immunol 2020;5:eabc3582.

(Accepted January 13, 2021; First Online December 15, 2021) Edited by WANG Wei-xia 